\title{
The Symptom Cluster-Based Approach to Individualize Patient-Centered Treatment for Major Depression
}

\author{
Steven Y. Lin, MD, and Michael B. Stevens, MD
}

Unipolar major depressive disorder is a common, disabling, and costly disease that is the leading cause of ill health, early death, and suicide in the United States. Primary care doctors, in particular family physicians, are the first responders in this silent epidemic. Although more than a dozen different antidepressants in 7 distinct classes are widely used to treat depression in primary care, there is no evidence that one drug is superior to another. Comparative effectiveness studies have produced mixed results, and no specialty organization has published recommendations on how to choose antidepressants in a rational, evidence-based manner. In this article we present the theory and evidence for an individualized, patient-centered treatment model for major depression designed around a targeted symptom cluster-based approach to antidepressant selection. When using this model for healthy adults with major depressive disorder, the choice of antidepressants should be guided by the presence of 1 of 4 common symptom clusters: anxiety, fatigue, insomnia, and pain. This model was built to foster future research, provide a logical framework for teaching residents how to select antidepressants, and equip primary care doctors with a structured treatment strategy to deliver optimal patient-centered care in the management of a debilitating disease: major depressive disorder. (J Am Board Fam Med 2014;27: 151-159.)

Keywords: Behavioral Sciences, Depression, Evidence-based Medicine, Medical Decision Making, Pharmacotherapy

Unipolar major depressive disorder is a common, debilitating chronic disease that affects 1 in 6 people in the United States during their lifetime. ${ }^{1,2}$ Although as many as 14 million US adults suffer from major depression in a given year, ${ }^{2}$ fewer than half of those affected received any kind of treatment in the previous 12 months. ${ }^{3}$ Among those who are being treated for major depression, fewer than one-third are receiving at least minimally ad-

This article was externally peer reviewed.

Submitted 6 May 2013; revised 23 July 2013; accepted 5 August 2013.

From the Center for Education and Research in Family and Community Medicine, Division of General Medical Disciplines, Department of Medicine, Stanford University School of Medicine, Stanford, CA (SYL); and the San JoseO'Connor Hospital Family Medicine Residency Program (affiliated with Stanford University School of Medicine), San Jose, CA (SYL, MBS).

Funding: none.

Conflict of interest: none declared.

Corresponding author: Steven Y. Lin, MD, 211 Quarry Road, Suite 405, Palo Alto, CA 94304 (E-mail: stevenlin@ stanford.edu). equate treatment, ${ }^{3}$ which is defined by evidencebased practice guidelines as either psychotherapy or appropriate pharmacotherapy. ${ }^{4-6}$ With 5 of 6 depressed US adults left untreated or poorly treated $^{3}$ and the economic burden of depression surpassing $\$ 83$ billion a year, ${ }^{7}$ major depressive disorder is a silent epidemic that warrants a vigorous primary care response.

Primary care doctors, especially family physicians, are the first responders in mental health care in the United States. ${ }^{8}$ Nearly three quarters of Americans who seek care for symptoms of major depression will go to a primary care doctor rather than a mental health specialist. ${ }^{8}$ Driven by changing public attitudes and growing acceptance of mental health treatment over the past 2 decades, the proportion of the adult population in the US receiving mental health care has increased to more than $20 \% .^{10}$ Most of this increased mental health care is provided by primary care doctors, ${ }^{3}$ two thirds of whom have limited or no access to psy- 
chotherapy or psychiatry referrals. ${ }^{11}$ Although pharmacotherapy may not be the first choice for mild to moderate symptoms of depression, without improved access to psychotherapy the use of antidepressants has become the primary choice of treatment for major depressive disorder. ${ }^{12}$ Primary care doctors now write more than two thirds of the 233 million annual prescriptions for antidepressants. ${ }^{13}$ In 2005, antidepressants surpassed antihypertensives to become the most commonly prescribed family of medications in the United States. ${ }^{14,15}$

Antidepressants are a heterogeneous family of medications that are pharmacologically divided into 7 distinct classes (Table 1): selective serotonin reuptake inhibitors (SSRIs), ${ }^{16-21}$ serotonin norepinephrine reuptake inhibitors (SNRIs), ${ }^{22-25}$ norepinephrine dopamine reuptake inhibitors (NDRIs), ${ }^{26}$ noradrenergic specific serotonergic antidepressants (NaSSAs), ${ }^{27,28}$ serotonin antagonist reuptake inhibitors (SARIs), ${ }^{29}$ serotonin partial agonist reuptake inhibitors, ${ }^{30}$ and tricyclic antidepressants (TCAs). ${ }^{31,32}$ There is another class of antidepressants, monoamine oxidase inhibitors, which is rarely used today in primary care but holds particular promise for patients who have failed multiple trials of new-generation medications. ${ }^{33}$ All antidepressants act directly on one or more monoamine neurotransmitter pathways, but the exact explanation of how they work is still unknown. ${ }^{34}$ Furthermore, research efforts to determine which antidepressants are the most effective in treating major depressive disorder have yielded no winners. ${ }^{35-41}$ Although antidepressants are clearly more effective than placebo in treating major depression, with a reasonable number needed to treat of $7,{ }^{42}$ the question of whether clinically significant differences exist between widely used antidepressants remains the subject of intense debate.

Comparative effectiveness meta-analyses designed to tease out differences in efficacy between antidepressants have produced mixed results. ${ }^{35-41}$ The first comprehensive effort in 2005 concluded that antidepressants do not differ substantially from one another and acknowledged that choosing the most appropriate agent for a given patient is difficult. ${ }^{35}$ An updated meta-analysis by the same US-based team in 2007 reached the same conclusion. ${ }^{36,37}$ In 2009, researchers based in Europe and Japan created substantial controversy when their data suggested that escitalopram and sertraline were supe- rior in efficacy and acceptability among commonly prescribed antidepressants. ${ }^{38,39}$ Their studies have been criticized for methodological shortcomings. ${ }^{43-48}$ The newest meta-analysis, which was published in 2011 includes the most up-to-date evidence, again did not detect any clinically important differences in effectiveness among antidepressants. ${ }^{40}$ Reflecting this continuing uncertainty, the latest practice guideline by the Agency for Health care Research and Quality does not recommend one agent over another and suggests only that differences in side effect profiles should be considered when choosing an antidepressant. ${ }^{41}$ To date, no specialty organization has offered recommendations on how to choose antidepressants in a rational, evidence-based manner, leaving primary care doctors on the front lines with little guidance. ${ }^{49}$

So how should primary care doctors select which antidepressants to use? In the absence of clear evidence from comparative effectiveness studies, a reasonable way to begin answering this question is to examine how psychiatrists select antidepressants. ${ }^{50}$ An important study in 2004 showed that the most influential factor on which the majority of psychiatrists based their antidepressant choices was the presence of a symptom cluster. ${ }^{50}$ The specific clinical features to which psychiatrists pay the most attention are anxiety, insomnia or hypersomnia, fatigue, anger or irritability, increased or decreased appetite, and melancholic or atypical symptoms. ${ }^{50}$ For example, in a large cohort of depressed patients with accompanying anxiety, psychiatrists were most likely to prescribe paroxetine (an SSRI with sedating properties) and least likely to prescribe fluoxetine (an SSRI with activating properties) or bupropion (an NDRI with activating properties). ${ }^{51}$ This suggests that certain "side effects" of antidepressants-for example, sedation or activationmay be capitalized on to treat specific symptoms of depression. A targeted, symptom cluster-based approach to choosing antidepressants reflects the belief of most psychiatrists that not all depression is the same ${ }^{50}$; depression subtypes exist, and those differences may potentially be used to guide drug selection in a logical way. ${ }^{5}$

The symptom cluster-based approach to antidepressant selection is popular among psychiatrists and savvy primary care doctors, ${ }^{50-52}$ but evidence supporting its use is limited. ${ }^{53,54}$ Systemic reviews have compared treatment strategies among de- 
Table 1. Commonly Prescribed Antidepressants in Primary Care

\begin{tabular}{|c|c|c|c|c|c|c|c|c|c|}
\hline Generic Name & $\begin{array}{l}\text { US Trade } \\
\text { Name }\end{array}$ & Class* & Dosage Forms & $\begin{array}{c}\text { Usual } \\
\text { Frequency }\end{array}$ & $\begin{array}{l}\text { Pregnancy } \\
\text { Category }^{\dagger}\end{array}$ & $\begin{array}{l}\text { Breastfeeding } \\
\text { Safety }^{\ddagger}\end{array}$ & $\begin{array}{c}\text { Generic } \\
\text { Available }\end{array}$ & $\begin{array}{c}\text { Retail } \\
\text { Available }\end{array}$ & Cost $\|^{\|}$ \\
\hline Amitriptyline & Elavil & TCA & Tablet & Once a day & $\mathrm{C}$ & NR & Yes & Yes & $\$$ \\
\hline \multirow[t]{3}{*}{ Bupropion } & Wellbutrin & NDRI & Tablet & $\begin{array}{l}\text { Three times } \\
\text { daily }\end{array}$ & $\mathrm{C}$ & NR & Yes & No & $\$ \$$ \\
\hline & Wellbutrin SR & & & Twice a day & & & Yes & No & $\$ \$$ \\
\hline & Wellbutrin XL & & & Once a day & & & Yes & No & $\$ \$ \$$ \\
\hline Citalopram & Celexa & SSRI & Tablet, solution & Once a day & $\mathrm{C}$ & $\mathrm{R}: \mathrm{B}$ & Yes & Yes & $\$$ \\
\hline Desvenlafaxine & Pristiq & SNRI & Tablet & Once a day & $\mathrm{C}$ & NR & No & No & $\$ \$ \$ \$$ \\
\hline Duloxetine & Cymbalta & SNRI & Capsule & Once a day & $\mathrm{C}$ & NR & No & No & $\$ \$ \$ \$$ \\
\hline Escitalopram & Lexapro & SSRI & Tablet, solution & Once a day & $\mathrm{C}$ & $\mathrm{R}: \mathrm{B}$ & Yes & No & $\$ \$ \$$ \\
\hline \multirow[t]{2}{*}{ Fluoxetine } & Prozac & SSRI & $\begin{array}{l}\text { Tablet, capsule, } \\
\text { solution }\end{array}$ & Once a day & $\mathrm{C}$ & NR & Yes & Yes & $\$$ \\
\hline & Prozac Weekly & & Capsule & $\begin{array}{r}\text { Once a } \\
\text { week }\end{array}$ & & & Yes & No & $\$ \$ \$$ \\
\hline \multirow[t]{2}{*}{ Fluvoxamine $^{\mathbb{I}}$} & Luvox & SSRI & Tablet & Twice a day & $\mathrm{C}$ & $\mathrm{R}: \mathrm{B}$ & Yes & No & $\$ \$ \$$ \\
\hline & Luvox CR & & Capsule & Once a day & & & No & No & $\$ \$ \$ \$$ \\
\hline Milnacipran ${ }^{\mathbb{I}}$ & Savella & SNRI & Tablet & Twice a day & $\mathrm{C}$ & NR & No & No & $\$ \$ \$$ \\
\hline \multirow[t]{2}{*}{ Mirtazapine } & Remeron & NaSSA & Tablet & Once a day & $\mathrm{C}$ & $\mathrm{R}: \mathrm{B}$ & Yes & No & $\$$ \\
\hline & $\begin{array}{r}\text { Remeron } \\
\text { SolTab }\end{array}$ & & $\begin{array}{l}\text { Oral } \\
\text { disintegrating } \\
\text { tablet }\end{array}$ & & & & Yes & No & $\$ \$$ \\
\hline Nefazodone ${ }^{* *}$ & Serzone & SARI & Tablet & Twice a day & $\mathrm{C}$ & NR & Yes & No & $\$ \$$ \\
\hline Nortriptyline & Pamelor & TCA & $\begin{array}{l}\text { Capsule, } \\
\text { solution }\end{array}$ & Once a day & $\mathrm{D}$ & NR & Yes & Yes & $\$$ \\
\hline \multirow[t]{2}{*}{ Paroxetine } & Paxil & SSRI & Tablet, solution & Once a day & $\mathrm{D}$ & Safe & Yes & Yes & $\$$ \\
\hline & Paxil CR & & Tablet & & & & Yes & No & $\$ \$ \$$ \\
\hline Sertraline & Zoloft & SSRI & Tablet, solution & Once a day & $\mathrm{C}$ & Safe & Yes & Yes & $\$$ \\
\hline \multirow[t]{2}{*}{ Trazodone } & Desyrel & SARI & Tablet & $\begin{array}{l}\text { Three times } \\
\text { daily }\end{array}$ & $\mathrm{C}$ & $\mathrm{R}: \mathrm{B}$ & Yes & Yes & $\$$ \\
\hline & Oleptro & & & Once a day & & & No & No & $\$ \$ \$$ \\
\hline \multirow[t]{3}{*}{ Venlafaxine } & Effexor & SNRI & Tablet & Twice a day & $\mathrm{C}$ & NR & Yes & No & $\$ \$$ \\
\hline & $\begin{array}{l}\text { Venlafaxine } \\
\text { ER }\end{array}$ & & & Once a day & & & Yes & No & $\$ \$ \$$ \\
\hline & Effexor XR & & Capsule & Once a day & & & No & No & $\$ \$ \$ \$$ \\
\hline Vilazodone $^{\dagger \dagger}$ & Viibryd & SPARI & Tablet & Once a day & $\mathrm{C}$ & NR & No & No & $\$ \$ \$ \$$ \\
\hline
\end{tabular}

*TCA, tricyclic antidepressant; NDRI, norepinephrine dopamine reuptake inhibitor; SSRI, selective serotonin reuptake inhibitor; SNRI, serotonin norepinephrine reuptake inhibitor; NaSSA, noradrenergic specific serotonergic antidepressant; SARI, serotonin antagonist reuptake inhibitor; SPARI, serotonin partial agonist reuptake inhibitor.

${ }^{\dagger} \mathrm{C}$, no adequate or well-controlled studies in humans; D, positive evidence of human fetal risk based on adverse reaction data or studies in humans.

${ }^{\ddagger} \mathrm{NR}$, not recommended; R:B, weigh risk-benefit; safe, safe for nursing; based on Lexicomp Online Clinical Databases (http:// online.lexi.com).

${ }^{\S}$ Available for a low monthly cost through programs offered by large chain stores (e.g., Walmart, Kroger, Sam’s Club, Target, Costco, CVS, Kmart, Walgreens). ${ }^{68}$

$\| \$=<\$ 50$ per month; $\$ \$=\$ 50$ to $\$ 100$ per month; $\$ \$ \$=\$ 100$ to $\$ 150$ per month; $\$ \$ \$ \$=>\$ 150$ per month; based on 2011 Consumer Reports Health Best Buy Drugs. ${ }^{68}$

II In the United States, fluvoxamine is approved only for obsessive-compulsive disorder; milnacipran is approved only for fibromyalgia; both agents are used off-label to treat depression. ${ }^{19,24}$

** Serzone, the brand name form of nefazodone, was discontinued in 2004 because of hepatotoxicity; generic nefazodone is available with a black box warning for liver failure. ${ }^{57}$

${ }^{+\dagger}$ Approved in 2011, vilazodone is the newest antidepressant in a novel therapeutic class; given that data is limited, it is not discussed in this article.

pressed patients with accompanying symptoms of anxiety, insomnia, pain, loss of energy, and atypical features. ${ }^{53,54}$ Although these studies were unable to draw reliable conclusions about the superiority of any antidepressant for a specific symptom cluster, the authors cautioned that very few trials in their 
analyses were correctly designed or adequately powered to test this approach. ${ }^{53,54}$ Since most of the available data are from analyzing subgroups in large studies that did not intentionally enroll patients with significant accompanying symptoms, the quality of actual head-to-head evidence is very low. ${ }^{53,54}$ Investigators have called for high-quality, prospectively designed, randomized head-to-head trials of commonly prescribed antidepressants in well-defined populations of patients with prominent symptom clusters. ${ }^{53,54}$ Such research has the promise of finally producing direct evidence for a more individualized, patient-centered method of choosing antidepressants to treat major depression in primary care.

Any primary care model for a symptom clusterbased approach to antidepressant selection must be centered on a set of commonly occurring symptoms, each of which may effectively be treated by a pharmacologically appropriate class or classes of antidepressants. Based on available evidence and expert consensus, the most common and clinically relevant symptoms accompanying depression are anxiety, fatigue, insomnia, and pain. ${ }^{49-54}$ Thus, these four symptoms are a logical starting point to conceive a treatment model. Each of these 4 symptoms is physiologically mediated by one or more monoamine neurotransmitter pathways. ${ }^{34}$ Anxiety is primarily regulated by serotonergic neurons projecting from the dorsal raphe nucleus in the brainstem to the limbic system that controls fear. ${ }^{34} \mathrm{Fa}-$ tigue is mediated through actions on the limbic cortex as well, but by norephinephrine pathways from the locus coeruleus, part of the reticular activating system that projects to the frontal cortex to control attention and concentration. ${ }^{34}$ Insomnia is caused by dysregulation in the brainstem sleep centers, which involve serotonin $2 \mathrm{~A}\left(5 \mathrm{HT}_{2 \mathrm{~A}}\right)$ receptors. ${ }^{34}$ Pain is thought to be mediated by both the serotonin and norepinephrine pathways acting directly to potentiate the pain-killing effects of the endogenous opioid system. ${ }^{55}$ Understanding how these core symptoms are related to deficiencies in specific neurotransmitters is the first step to choosing the most appropriate types of antidepressants for each symptom cluster.

Anxiety is the first symptom to consider in the current effort to build a rational treatment model for depression in primary care (Table 2). As noted above, it is regulated by serotonergic neurons acting on the limbic system that controls fear. ${ }^{34}$ It is
Table 2. Recommended Treatment for Depression with Anxiety

\begin{tabular}{lccl}
\hline Symptom Cluster & $\begin{array}{c}\text { Recommended } \\
\text { Classes }\end{array}$ & $\begin{array}{c}\text { Classes } \\
\text { to Avoid }\end{array}$ & $\begin{array}{c}\text { First-line } \\
\text { Antidepressants }\end{array}$ \\
\hline Anxiety & SSRI & NDRI & Citalopram \\
$\begin{array}{l}\text { Tearfulness } \\
\text { Obsessive- } \\
\text { compulsiveness }\end{array}$ & & SNRI & $\begin{array}{l}\text { Escitalopram } \\
\text { Fluvoxamine } \\
\text { Sertraline }\end{array}$ \\
\hline
\end{tabular}

NDRI, norepinephrine dopamine reuptake inhibitor; SSRI, selective serotonin reuptake inhibitor; SNRI, serotonin norepinephrine reuptake inhibitor.

important to note that the same neurons arising from the brainstem that mediate anxiety also project to the frontal cortex to control mood and to the basal ganglia to influence obsessions and compulsions. $^{34}$ The triad of anxiety, tearfulness, and obsessive-compulsive behaviors is part of the "serotonin deficiency syndrome," 34 a common symptom cluster encountered in a subpopulation of patients with major depressive disorder. Individuals with this symptom cluster may benefit most from an SSRI (Table 2). Supporting the superiority of SSRIs in this clinical setting is evidence that, in contrast to other antidepressant classes, most SSRIs are also approved by the US Food and Drug Administration (FDA) to treat generalized anxiety disorder and panic disorder, and only SSRIs are approved to treat obsessive-compulsive disorder. ${ }^{40,41}$ Although some SNRIs also are approved to treat anxiety disorder, patients with this symptom cluster may be less likely to benefit from them because of sympathetic (fight or flight) effects of norepinephrine on the cardiovascular and nervous systems, which can provoke anxiety. ${ }^{34}$ Patients with this symptom cluster are also least likely to benefit from an NDRI, given its lack of serotonin activity and more activating properties. ${ }^{51}$ Under the current proposal, the best antidepressant to treat a depressed patient with anxiety, tearfulness, and obsessive-compulsive behavior is an SSRI such as citalopram, escitalopram, fluvoxamine, or sertraline (Table 2). Two other SSRIs with important activating (fluoxetine) and sedating (paroxetine) action will be examined later in the context of other symptom clusters.

Fatigue is the second symptom under consideration (Table 3). Energy, attention, concentration, and related cognitive functions are mediated by norepinephrine. ${ }^{34}$ In contrast to the anxious and tearful patient described earlier, those with fatigue- 
Table 3. Recommended Treatment for Depression with Fatigue

\begin{tabular}{|c|c|c|c|}
\hline $\begin{array}{l}\text { Symptom } \\
\text { Cluster }\end{array}$ & $\begin{array}{l}\text { Recommended } \\
\text { Classes }\end{array}$ & $\begin{array}{l}\text { Classes } \\
\text { to Avoid }\end{array}$ & $\begin{array}{c}\text { First-line } \\
\text { Antidepressants }\end{array}$ \\
\hline Fatigue & NDRI & NaSSA & Bupropion \\
\hline Anhedonia & SNRI & SARI & Desvenlafaxine \\
\hline \multirow[t]{2}{*}{ Weight gain } & Activating SSRI & & Fluoxetine \\
\hline & & & Venlafaxine \\
\hline
\end{tabular}

NaSSA, noradrenergic specific serotonergic antidepressant; NDRI, norepinephrine dopamine reuptake inhibitor; SARI, serotonin antagonist reuptake inhibitor; SNRI, serotonin norepinephrine reuptake inhibitor; SSRI, selective serotonin reuptake inhibitor.

dominant depression often present with blunted affect, emotional withdrawal, weight gain, or anhedonia (loss of pleasure). ${ }^{5}$ These so-called atypical symptoms of depression are regulated by dopaminergic neurons projecting from the ventral tegmental area of the brainstem to the cerebral cortex. ${ }^{34}$ Since deficiencies of norepinephrine and dopamine are thought to be the cause of atypical depression, recommending an SNRI (to increase norepinephrine) or NDRI (to boost both norepinephrine and dopamine) is the logical choice. Fluoxetine, an unusual SSRI with some norepinephrine reuptake inhibition, ${ }^{34}$ is the most activating SSRI available and is preferred by most psychiatrists to treat depression with fatigue. ${ }^{52}$ Under the current proposal, the best antidepressants for treating the symptom cluster of fatigue, weight gain, and anhedonia should be bupropion (NDRI), venlafaxine or desvenlafaxine (SNRIs), and fluoxetine (SSRI) (Table 3). Two other SNRIs, duloxetine and milnacipran, with FDA indications to treat chronic pain, will be discussed later in the context of another symptom cluster. Fatigued patients are least likely to benefit from sedating antidepressants like NaSSAs and SARIs, which are better reserved for treating insomnia. ${ }^{29}$

Insomnia is the third symptom under consideration (Table 4). As discussed earlier, insomnia is regulated by sleep centers in the brainstem, which involve $5 \mathrm{HT}_{2 \mathrm{~A}}$ receptors. ${ }^{34}$ Antidepressant classes with powerful $5 \mathrm{HT}_{2 \mathrm{~A}}$ blocking activity, such as NaSSAs (mirtazapine) and SARIs (nefazodone and trazodone), should be particularly effective at alleviating insomnia and improving sleep architecture. ${ }^{29}$ Studies have shown that mirtazapine significantly shortens time to sleep onset, increases total sleep duration, and improves sleep efficiency. ${ }^{29}$ Psychiatrists prefer SARIs such as nefazodone and trazodone over other agents for treating depression with insomnia, whereas primary care doctors tend to choose paroxetine, a unique SSRI with prominent anticholinergic action and sedating properties. ${ }^{52}$ Depressed patients with insomnia also occasionally present with clinical indications of weight loss and hyperarousal, especially if their depression is complicated by posttraumatic stress disorder. ${ }^{56}$ Paroxetine and mirtazapine are recommended as first-line treatments for posttraumatic stress disorder by the National Institute for Clinical Excellence $^{56}$ and are likely the best choices for patients with insomnia plus hyperarousal. Mirtazapine is a good choice for restoring body weight when weight loss is a concern. ${ }^{27,28}$ In contrast to the fatigued patient discussed earlier, antidepressants like SNRIs and NDRIs are least likely to benefit patients with insomnia since they may be too activating. Under the current proposal, the best antidepressants for treating insomnia, hyperarousal, and weight loss are mirtazapine, paroxetine, trazodone, and nefazodone (Table 4). Physicians should be aware that Serzone (Bristol-Meyers Squibb Co, New York, NY), one of the brand names of nefazodone, was discontinued in the United States in 2004 because of hepatotoxicity. ${ }^{57}$ Generic nefazodone remains available, but it is rarely used because of a black box warning for fulminant liver failure. ${ }^{57}$

Pain is the last symptom to consider in the current effort to build a rational treatment model for depression (Table 5). Pain is thought to be mediated by both serotonin and norepinephrine acting directly to potentiate the analgesic effects of the endogenous opioid system. ${ }^{55}$ Since deficiencies of both serotonin and norepinephrine are present, it is logical to recommend an SNRI. Duloxetine is

Table 4. Recommended Treatment for Depression with Insomnia

\begin{tabular}{|c|c|c|c|}
\hline $\begin{array}{l}\text { Symptom } \\
\text { Cluster }\end{array}$ & $\begin{array}{l}\text { Recommended } \\
\text { Classes }\end{array}$ & $\begin{array}{l}\text { Classes } \\
\text { to Avoid }\end{array}$ & $\begin{array}{c}\text { First-line } \\
\text { Antidepressants }\end{array}$ \\
\hline Insomnia & NaSSA & NDRI & Mirtazapine \\
\hline Hyperarousal & SARI & SNRI & Nefazodone \\
\hline \multirow[t]{2}{*}{ Weight loss } & Sedating SSRI & & Paroxetine \\
\hline & & & Trazodone \\
\hline
\end{tabular}

NaSSA, noradrenergic specific serotonergic antidepressant; NDRI, norepinephrine dopamine reuptake inhibitor; SARI, serotonin antagonist reuptake inhibitor; SNRI, serotonin norepinephrine reuptake inhibitor; SSRI, selective serotonin reuptake inhibitor. 
Table 5. Recommended Treatment for Depression with Pain

\begin{tabular}{lccl}
\hline $\begin{array}{l}\text { Symptom } \\
\text { Cluster }\end{array}$ & $\begin{array}{c}\text { Recommended } \\
\text { Classes }\end{array}$ & $\begin{array}{c}\text { Classes } \\
\text { to Avoid }\end{array}$ & $\begin{array}{c}\text { First-line } \\
\text { Antidepressants }\end{array}$ \\
\hline $\begin{array}{l}\text { Chronic pain } \\
\text { Headache }\end{array}$ & TCA & None & $\begin{array}{l}\text { Amitriptyline } \\
\text { SNRI }\end{array}$ \\
Somatization & & & $\begin{array}{l}\text { Duloxetine } \\
\text { Milnacipran }\end{array}$ \\
& & & Nortriptyline \\
\hline
\end{tabular}

SNRI, serotonin norepinephrine reuptake inhibitor; TCA, tricyclic antidepressant.

a SNRI that is FDA approved to treat major depression as well as painful diabetic peripheral neuropathy, fibromyalgia, and chronic musculoskeletal pain. ${ }^{23}$ Milnacipran is an SNRI that is approved in the United States only for the treatment of fibromyalgia, but it is popular in other countries for treatment of depression. ${ }^{24}$ There are only a few studies that directly compare an SNRI with other antidepressants for treating depression with pain, and all these studies are flawed and underpowered. ${ }^{53}$ It is hoped that future research will elucidate the exact role of SNRIs in the treatment of painful depression. What has been used for decades as effective treatment for a number of chronic pain conditions-including idiopathic neuropathy, ${ }^{58}$ fibromyalgia, ${ }^{59}$ painful diabetic neuropathy, ${ }^{60}$ prophylaxis of episodic migraine, ${ }^{61}$ and chronic musculoskeletal pain ${ }^{62}$-are TCAs such as amitriptyline and nortriptyline. Although TCAs are older and in general less well-tolerated than newer antidepressants, they have a similar if not better efficacy in treating depression. ${ }^{63}$ TCAs also have the added advantage of $>50$ years of experience in the hands of psychiatrists and primary care doctors. ${ }^{63}$ Therefore, under the current proposal, the best antidepressants to treat depression with chronic pain are duloxetine, milnacipran, amitriptyline, and nortriptyline (Table 5).

An individualized, patient-centered treatment model for depression, created around a targeted symptom cluster-based approach to antidepressant selection, is described herein (Tables 2 to 5). In healthy adults with unipolar major depressive disorder, the choice of antidepressants should be guided primarily by the patient's dominant symptom cluster. Patients do not need to have all the symptoms in a symptom cluster to warrant treatment. Further distinction between medications in the same cluster may be guided by comorbid medical or psychiatric conditions, previous response (or lack thereof) to a particular agent, preexisting renal or hepatic dysfunction, drug-drug interactions, frequency of dosing, and other factors. Pregnancy raises special concerns, especially with regard to teratogenicity and safety during breastfeeding. Sertraline has the best safety record in pregnant patients, whereas paroxetine should be avoided if possible. ${ }^{64,65}$ Age is also an important determinant. Fluoxetine has the best evidence in children and adolescents and is generally considered first-line treatment in this population. ${ }^{66,67}$ Lastly, the cost of medications has a significant impact on patients and the health care system. Antidepressants range from $\$ 4$ per month for older generics to $>\$ 500$ per month for newer brand name drugs. ${ }^{68}$ One study comparing depression remission rates with costs of treatment for different medications suggested that escitalopram is the most cost-effective antidepressant in the primary care setting, at least in Europe. ${ }^{69}$ These European estimates may differ from the US experience because of significant differences in price for some medications.

This proposed symptom cluster-based treatment model is based on the highest-quality evidence available, plausible neurobiological mechanisms, and years of practical experience. Veteran primary care doctors may find these recommendations comparable to their current practices, which were developed through trial and error. Nevertheless, direct evidence to support the use of a symptom cluster-based approach is very limited and complicated by studies with flawed designs and inadequate power. ${ }^{53,54}$ This model should be vigorously tested with high-quality, prospectively designed, randomized head-to-head trials of commonly prescribed antidepressants in populations of patients with well-defined symptom clusters. Future research should also strive to elucidate the complete mechanism of action for antidepressants, which may lead to the discovery of new biological targets for rational drug design. Lastly, primary care doctors need to know what to do after an initial antidepressant fails. No strategy - whether by augmentation with a second antidepressant or switching antidepressants within or between classes- has been proven superior. $^{70-72}$

\section{Conclusion}

Unipolar major depressive disorder is a common, disabling, and costly disease that is the leading 
cause of ill health, early death, and suicide in the United States. Primary care doctors, particularly family physicians, are the first responders in this silent epidemic. While there are more than a dozen different antidepressants in 7 distinct classes that are widely used to treat depression in primary care, there is no evidence that one drug is superior to another. Comparative effectiveness studies have produced mixed results, and no specialty organization has published recommendations on how to choose antidepressants in a rational, evidencebased manner. In this article we presented the theory and evidence for an individualized, patientcentered treatment model for major depression that is designed around a targeted symptom cluster-based approach to antidepressant selection. Using this model in healthy adults with major depressive disorder, the choice of antidepressants should be guided by the presence of 1 of 4 common symptom clusters: anxiety, fatigue, insomnia, and paineach of which may be effectively treated by an appropriate class or classes of antidepressants. This model was created to act as a practical construct to foster the design of future prospective, randomized trials that will put the symptom cluster-based approach to the test. In addition, this model provides a logical framework for teaching residents how to choose antidepressants that goes beyond arbitrary trial and error. Finally, the ultimate goal of the model is to equip primary care doctors with a structured treatment strategy to deliver optimal patientcentered care in the battle against depression.

\section{References}

1. Kessler RC, Berglund P, Demler O, et al. Lifetime prevalence and age-of-onset distributions of DSM-IV disorders in the National Comorbidity Survey Replication. Arch Gen Psychiatry 2005;62:593-602.

2. Kessler RC, Berglund P, Demler O, et la; National Comorbidity Survey Replication. The epidemiology of major depressive disorder: results from the $\mathrm{Na}$ tional Comorbidity Survey Replication (NCS-R). JAMA 2003;289:3095-105.

3. Wang PS, Lane M, Olfson M, Pincus HA, Wells KB, Kessler RC. Twelve-month use of mental health services in the United States: results from the $\mathrm{Na}$ tional Comorbidity Survey Replication. Arch Gen Psychiatry 2005;62:629-40.

4. Agency for Health Care Policy and Research. Depression Guideline Panel, Vol 2: treatment of major depression, clinical practice guideline, no 5. Rockville, MD: Agency for Health Care Policy and Re- search, Public Health Service, US Dept of Health and Human Services; 1993.

5. American Psychiatric Association. Practice guideline for treatment of patients with major depressive disorder. 2nd ed. Washington, DC: American Psychiatric Association Press; 2000.

6. Qaseem A, Snow V, Denberg TD, Forciea MA, Owens DK; Clinical Efficacy Assessment Subcommittee of American College of Physicians. Using second-generation antidepressants to treat depressive disorders: a clinical practice guideline from the American College of Physicians. Ann Intern Med 2008;149:725-33.

7. Greenberg PE, Kessler RC, Birnbaum HG, et al. The economic burden of depression in the United States: how did it change between 1990 and 2000? J Clin Psychiatry 2003;64:1465-75.

8. Montano CB. Recognition and treatment of depression in a primary care setting. J Clin Psychiatry 1994;55:18-34.

9. Mojtabai R. Americans' attitudes toward mental health treatment seeking: 1990-2003. Psychiatr Serv 2007;58:642-51.

10. Kessler RC, Demler O, Frank RG, et al. Prevalence and treatment of mental disorders, 1990 to 2003. N Engl J Med 2005;352:2515-23.

11. Cunningham PJ. Beyond parity: primary care physicians' perspectives on access to mental health care. Health Aff (Millwood) 2009;28:w490-501.

12. Olfson M, Marcus SC. National patterns in antidepressant medication treatment. Arch Gen Psychiatry 2009;66:848-56.

13. Mark TL, Levit KR, Buck JA. Datapoints: psychotropic drug prescriptions by medical specialty. Psychiatr Serv 2009;60:1167.

14. Cherry DK, Woodwell DA, Rechtsteiner EA. National Ambulatory Medical Care Survey: 2005 summary. Advance Data From Vital and Health Statistics; No. 387. Hyattsville, MD: National Center for Health Statistics; 2007.

15. Middelton K, Him E, Xu J. National Hospital Ambulatory Medical Care Survey: 2005 Outpatient Department Summary. Adv Data 2007;(389):1-34.

16. Cipriani A, Purgato M, Furukawa TA, et al. Citalopram versus other anti-depressive agents for depression. Cochrane Database Syst Rev 2012;(7): CD006534.

17. Cipriani A, Santilli C, Furukawa TA, et al. Escitalopram versus other antidepressive agents for depression. Cochrane Database Syst Rev 2009;(2): CD006532.

18. Cipriani A, Brambilla P, Furukawa T, et al. Fluoxetine versus other types of pharmacotherapy for depression. Cochrane Database Syst Rev 2005;(4): CD004185.

19. Omori IM, Watanabe N, Nakagawa A, et al. Fluvoxamine versus other anti-depressive agents for 
depression. Cochrane Database Syst Rev 2010;(3): CD006114.

20. Katzman MA, Tricco AC, McIntosh D, et al. Paroxetine versus placebo and other agents for depressive disorders: a systematic review and meta-analysis. J Clin Psychiatry 2007;68:1845-59.

21. Cipriani A, La Ferla T, Furukawa TA, et al. Sertraline versus other antidepressive agents for depression. Cochrane Database Syst Rev 2010;(4):CD006117.

22. Thase ME, Kornstein SG, Germain JM, Jiang Q, Guico-Pabia C, Ninan PT. An integrated analysis of the efficacy of desvenlafaxine compared with placebo in patients with major depressive disorder. CNS Spectr 2009;14:144-54.

23. Cipriani A, Koesters M, Furukawa TA, et al. Duloxetine versus other anti-depressive agents for depression. Cochrane Database Syst Rev 2012;(10):CD006533.

24. Nakagawa A, Watanabe N, Omori IM, et al. Milnacipran versus other antidepressive agents for depression. Cochrane Database Syst Rev 2009;(3):CD006529.

25. Smith D, Dempster C, Glanville J, Freemantle N, Anderson I. Efficacy and tolerability of venlafaxine compared with selective serotonin reuptake inhibitors and other antidepressants: a meta-analysis. Br J Psychiatry 2002;180:396-404.

26. Dhillon S, Yang LP, Curran MP. Bupropion: a review of its use in the management of major depressive disorder. Drugs 2008;68:653-89.

27. Watanabe N, Omori IM, Nakagawa A, et al. Mirtazapine versus other antidepressive agents for depression. Cochrane Database Syst Rev 2011;(12): CD006528.

28. Watanabe N, Omori IM, Nakagawa A, et al; Multiple Meta-Analyses of New Generation Antidepressants (MANGA) Study Group. Mirtazapine versus other antidepressants in the acute-phase treatment of adults with major depression: systematic review and meta-analysis. J Clin Psychiatry 2008;69:1404-15.

29. Thase ME. Antidepressant treatment of the depressed patient with insomnia. J Clin Psychiatry 1999;60:28-31.

30. Laughren TP, Gobburu J, Temple RJ, et al. Vilazodone: clinical basis for the US Food and Drug Administration's approval of a new antidepressant. J Clin Psychiatry 2011;72:1166-73.

31. Guaiana G, Barbui C, Hotopf M. Amitriptyline for depression. Cochrane Database Syst Rev 2007;(3): CD004186.

32. Mottram P, Wilson K, Strobl J. Antidepressants for depressed elderly. Cochrane Database Syst Rev. 2006;(1):CD003491.

33. Fekadu A, Rane LJ, Wooderson SC, Markopoulou K, Poon L, Cleare AJ. Prediction of longer-term outcome of treatment-resistant depression in tertiary care. Br J Psychiatry 2012;201:369-75.

34. Stahl SM. Essential psychopharmacology: neuroscientific basis and practical applications. 2nd ed. Cambridge, UK: Cambridge University Press; 2000.
35. Hansen RA, Gartlehner G, Lohr KN, Gaynes BN, Carey TS. Efficacy and safety of second-generation antidepressants in the treatment of major depressive disorder. Ann Intern Med 2005;143:415-26.

36. Gartlehner G, Hansen RA, Thieda P, et al. Comparative effectiveness of second-generation antidepressants in the pharmacologic treatment of adult depression. Rockville, MD: Agency for Healthcare Research and Quality, US Dept of Health and Human Services; 2007.

37. Gartlehner G, Gaynes BN, Hansen RA, et al. Comparative benefits and harms of second-generation antidepressants: background paper for the American College of Physicians. Ann Intern Med 2008;149: 734-50.

38. Cipriani A, Furukawa TA, Salanti G, et al. Comparative efficacy and acceptability of 12 new-generation antidepressants: a multiple-treatments meta-analysis. Lancet 2009;373:746-58.

39. Cipriani A, Furukawa TA, Geddes JR, et al; MANGA Study Group. Does randomized evidence support sertraline as first-line antidepressant for adults with acute major depression? A systematic review and meta-analysis. J Clin Psychiatry 2008;69: 1732-42.

40. Gartlehner G, Hansen RA, Morgan LC, et al. Comparative benefits and harms of second-generation antidepressants for treating major depressive disorder: an updated meta-analysis. Ann Intern Med 2011;155:772-85.

41. Gartlehner G, Hansen RA, Morgan LC, et al. Second-generation antidepressants in the pharmacologic treatment of adult depression: an update of the 2007 Comparative Effectiveness Review. Rockville, MD: Agency for Healthcare Research and Quality, US Dept of Health and Human Services; 2011.

42. Arroll B, Elley CR, Fishman T, et al. Antidepressants versus placebo for depression in primary care. Cochrane Database Syst Rev 2009;(3):CD007954.

43. Gartlehner G, Gaynes BN, Hansen RA, Lohr KN. Ranking antidepressants. Lancet 2009;373:1761.

44. Jefferson T. Ranking antidepressants. Lancet 2009; 373:1759.

45. Ioannidis JP. Ranking antidepressants. Lancet 2009; 373:1759-60.

46. Seyringer ME, Kasper S. Ranking antidepressants. Lancet 2009;373:1760-1.

47. Turner E, Moreno SG, Sutton AJ. Ranking antidepressants. Lancet 2009;373:1760.

48. Schwan S, Hallberg P. Ranking antidepressants. Lancet 2009;373:1761.

49. Gartlehner G, Thaler K, Hill S, Hansen RA. How should primary care doctors select which antidepressants to administer? Curr Psychiatry Rep 2012;14: 360-9

50. Zimmerman M, Posternak M, Friedman M, et al. Which factors influence psychiatrists' selection of antidepressants? Am J Psychiatry 2004;161:1285-9. 
51. Kim HM, Zivin K, Ganoczy D, et al. Predictors of alternative antidepressant agent initiation among U.S. veterans diagnosed with depression. Pharmacoepidemiol Drug Saf 2010;19:1049-56.

52. Garrison GD, Levin GM. Factors affecting prescribing of the newer antidepressants. Ann Pharmacother 2000;34:10-4.

53. Thaler KJ, Morgan LC, Van Noord M, et al. Comparative effectiveness of second-generation antidepressants for accompanying anxiety, insomnia, and pain in depressed patients: a systematic review. Depress Anxiety 2012;29:495-505.

54. Gaynes BN, Farley JF, Dusetzina SB, et al. Does the presence of accompanying symptom clusters differentiate the comparative effectiveness of second-line medication strategies for treating depression? Depress Anxiety 2011;28:989-98.

55. Ozdemir E, Gursoy S, Bagcivan I. The effects of serotonin/norepinephrine reuptake inhibitors and serotonin receptor agonist on morphine analgesia and tolerance in rats. J Physiol Sci 2012;62:317-23.

56. National Collaborating Centre for Mental Health. Post-traumatic stress disorder (PTSD): the management of PTSD in adults and children in primary and secondary care. London: National Institute for Clinical Excellence; 2005.

57. Wikipedia. Nefazodone. Updated November 3, 2013. Available from: http://en.wikipedia.org/wiki/ Nefazodone. Accessed November 8, 2013.

58. Moore RA, Derry S, Aldington D, Cole P, Wiffen PJ. Amitriptyline for neuropathic pain and fibromyalgia in adults. Cochrane Database Syst Rev 2012; (12):CD008242.

59. Goldenberg DL, Burckhardt C, Crofford L. Management of fibromyalgia syndrome. JAMA 2004;292: 2388-95.

60. Bril V, England J, Franklin GM, et al; American Academy of Neurology; American Association of Neuromuscular and Electrodiagnostic Medicine; American Academy of Physical Medicine and Rehabilitation. Evidence-based guideline: treatment of painful diabetic neuropathy: report of the American Academy of Neurology, the American Association of Neuromuscular and Electrodiagnostic Medicine, and the American Academy of Physical Medicine and Rehabilitation. PM R 2011;3:345-52.

61. Loder E, Burch R, Rizzoli P. The 2012 AHS/AAN guidelines for prevention of episodic migraine: a summary and comparison with other recent clinical practice guidelines. Headache 2012;52:930-45.
62. American Society of Anesthesiologists Task Force on Chronic Pain Management; American Society of Regional Anesthesia and Pain Medicine. Practice guidelines for chronic pain management: an updated report by the American Society of Anesthesiologists Task Force on Chronic Pain Management and the American Society of Regional Anesthesia and Pain Medicine. Anesthesiology 2010;112:810-33.

63. Barbui C, Hotopf M. Amitriptyline v. the rest: still the leading antidepressant after 40 years of randomised controlled trials. Br J Psychiatry 2001;178: 129-44.

64. Yonkers KA, Wisner KL, Stewart DE, et al. The management of depression during pregnancy: a report from the American Psychiatric Association and the American College of Obstetricians and Gynecologists. Gen Hosp Psychiatry 2009;31:403-13.

65. Stewart DE. Clinical practice. Depression during pregnancy. N Engl J Med 2011;365:1605-11.

66. Hetrick SE, McKenzie JE, Cox GR, Simmons MB, Merry SN. Newer generation antidepressants for depressive disorders in children and adolescents. Cochrane Database Syst Rev 2012;(11):CD004851.

67. Hetrick S, Merry S, McKenzie J, Sindahl P, Proctor M. Selective serotonin reuptake inhibitors (SSRIs) for depressive disorders in children and adolescents. Cochrane Database Syst Rev 2007;(3):CD004851.

68. Consumer Reports Health Best Buy Drugs. Antidepressants: summary of recommendations. September 2011. Available from: http://www.consumerreports. org/health/best-buy-drugs/antidepressants.htm. Accessed November 8, 2013.

69. Ramsberg J, Asseburg C, Henriksson M. Effectiveness and cost-effectiveness of antidepressants in primary care: a multiple treatment comparison metaanalysis and cost-effectiveness model. PLoS One 2012;7:e42003.

70. Ruhé HG, Huyser J, Swinkels JA, Schene AH. Switching antidepressants after a first selective serotonin reuptake inhibitor in major depressive disorder: a systematic review. J Clin Psychiatry 2006;67: $1836-55$.

71. Papakostas GI. Managing partial response or nonresponse: switching, augmentation, and combination strategies for major depressive disorder. J Clin Psychiatry 2009;70:16-25.

72. Connolly KR, Thase ME. If at first you don't succeed: a review of the evidence for antidepressant augmentation, combination and switching strategies. Drugs 2011;71:43-64. 